\title{
Evaluation of Calcium Hydroxide Apexification in Immature Permanent Incisors
}

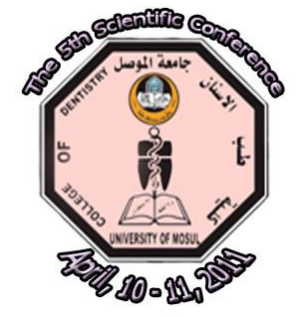

\begin{abstract}
Aims of the Study: The aim of the present study is to identify the effectiveness of tgpaste of calcium hydroxide with barium sulfate in inducing a calcified apical barrier of an incompletely formed root in necrotic permanent incisors of children. Materials and Methods: Twenty children with twenty teeth with pulpal necrotic and an incompletely formed apex were included in this study. Working length determination, instrumentation, irrigation and dryness were carried out for the root canals then paste of non setting calcium hydroxide injected inside the canal and after each 3 months the patients were recalled to check the calcified apical barrier formation. Results: The average age of patients was $\wedge$ years. The mean duration for apical barrier formation was 6.813 \pm 1.1 months (range 6-12 months). Discussion: The use of calcium hydroxide in apical barrier formation has shown promising results. Because of its enhanced success rate, easy availability for clinician and affordability for patients, it has gained widest acceptance all around the world. Conclusions: It is generally agreed that calcium hydroxide is the major ingredient responsible for stimulating the desired calcific closure of the apical area of non-vital immature permanent incisors.
\end{abstract}

Prof $\operatorname{Dr}$ Khidhair A Al-Jumaili (BDS, CES, DSO); Lect Baydaa AO Al-Rawi (BDS, MSc); Asst Prof Aisha A Qasim (BDS, MSc)

Department of Pedodontics, Orthodontics and Preventive Dentistry, Dentistry College, Mosul University

Key words: Calcium hydroxide, immature, permanent, non-vital.

Q) ental trauma in young permanent tooth may lead to non-vitality, if not intervened at an early stage. The treatment of non-vital immature teeth is a great challenge to clinician, as the root formation has not completed and open apex is found in the developing roots of immature teeth, which closes approximately 3 years after eruption of the tooth. For condensing gutta-percha, there should be an apex barrier to prevent extrusion of cement and gutta-percha into the periapical area causing trauma to the periapical tissues. ${ }^{(1)}$

The procedural term apexification refers to that method of treatment aimed at inducing apical repair as a hard tissue barrier across an open apex. This technique usually refers to endodontic management of the pulpless permanent tooth with an open or even 'blunderbuss' apex. $^{(2)}$

The procedure requires the chemomechanical debridement of the canal followed by placement of an intracanal medicament to assist or stimulate apical healing and formation of an apical barrier. The most common material used in apexification is calcium hydroxide. ${ }^{(3)}$

The composition of the apical barrier seems to vary. Cementum can form the apical bridge $^{(4)}$ and has been reported to have been deposited along the walls of the root canal even to the junction of the middle and cervical thirds. ${ }^{(5)}$ Dentine and bone have also been reported to 
have formed ${ }^{(6)}$ but the most common result seems to be a combination of all three tissues ${ }^{(7)}$ with connective tissue and calcium hydroxide sometimes mixed in with them. ${ }^{(8)}$

Hertwig's epithelial root sheath is considered to be an important tissue in the development of the apical barrier and may not always be irreparably damaged. ${ }^{(9)}$

Hertwig's sheath appears to be a resistant organ which can survive periapical inflammation and then continue its role of organization of root development when the inflammatory process is eliminated. ${ }^{(10)}$

The aim of the present study is to identify the effectiveness of tgpaste of calcium hydroxide with barium sulfate in inducing a calcified apical barrier or continued apical development of an incompletely formed root in necrotic permanent incisors of children.

\section{MATERIALS AND METHODS}

After detailed history and thorough clinical and radiographical examinations, twenty children with twenty teeth with pulpal necrotic and an incompletely formed apex (Figure 1) were included in this study at Department of Peadiatric Dentistry, College of Dentistry, University of Mosul.

First, the affected tooth was anesthetized with local anesthetic agent (Septodont, France), and an access opening was made into the pulp chamber. A suitable size of K-file (Technical \& General Ltd, UK) was placed in the root canal, and a radiograph was taken to establish the root length accurately within $1 \mathrm{~mm}$ of the radiographic apex (Figure 2). It is important to avoid placing the instrument through the apex, which might injure the epithelial diaphragm. ${ }^{(1)}$

After the remnants of the pulp were removed using barbed broaches and files (Technical \& General Ltd, UK), the canal was carefully instrumented to completely remove necrotic debris and the canal was flooded with hydrogen peroxide to aid in the removal of debris. The canal was then irrigated with sodium hypochlorite $(1 \% \mathrm{NaOCl})$ and saline and then dried with large paper points and loose cotton, a cotton pellet with camphorated mono-parachlorophenol (CMCP) (Produits Dentaires SA, Switzerland) was placed in the pulp chamber and the seal was completed with a layer of reinforced zinc oxide-eugenol cement (Produits Dentaires SA, Vevey/ Switzerland). ${ }^{(1)}$

Another visit was performed 4-5 days later, if there was any evidence of hemorrhage, exudates or sensitivity of the treated tooth, cleaning and irrigation with sodium hypochlorite (1\% $\mathrm{NaOCl}$ ) and saline of the root canal was repeated. Then after 4-5 days later, with absence of hemorrhage, exudates or sensitivity of the treated tooth, a paste of non setting calcium hydroxide with barium sulfate (tgpaste, Technical \& General Ltd, UK), manufactured in a form of syringe with disposable tip was inserted in the root canal to the correct working length and the paste was injected easily by withdrawing of the syringe's tip from the canal till the canal orifice, then the access opening was sealed with a layer of reinforced zinc oxide-eugenol cement ${ }^{(1)}$ (Figure 3 ).

The patient was re-examined after 3 months. Non setting calcium hydroxide paste was changed every 3 months if there was evidence of resorption of the paste. Until the closure occurred or calcific bridge was observed radiographically (Figure 4). An apical barrier formation was confirmed by using a size 30 paper point to check for the presence of a resistant 'stop' and absence of hemorrhage, exudates or sensitivity. Then conventional obturation with gutta percha was done $^{(1)}$ (Figure 5). 


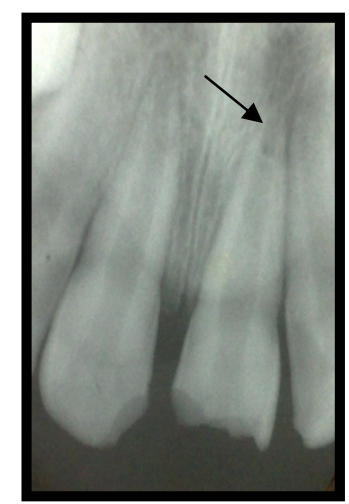

Figure (1): Pulpal necrotic tooth and an incompletely

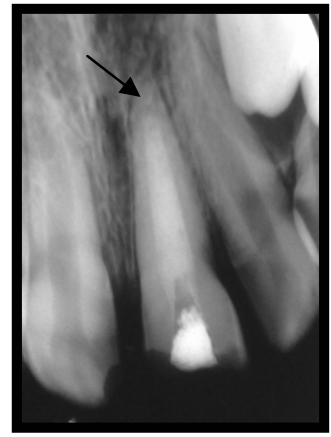

Figure (4): After 6 months apical barrier closure

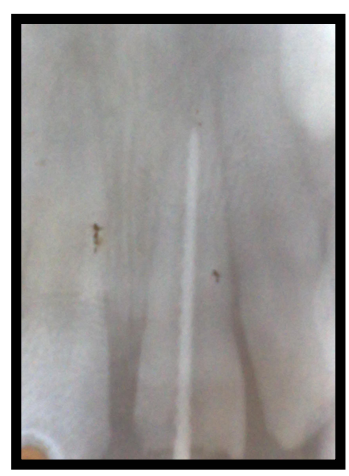

Figure (2): Working length determination

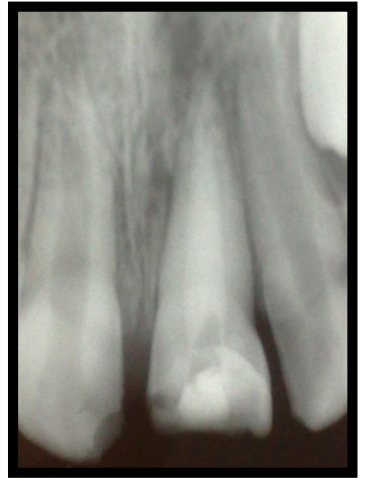

Figure (3): Calcium hydroxide paste injection

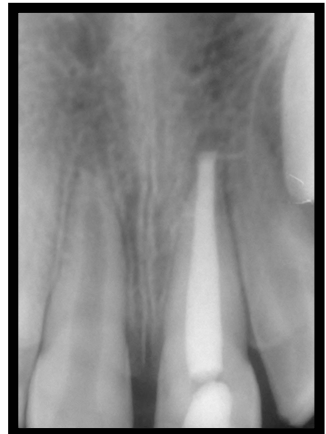

Figure (5): Gutta percha obturation

\section{RESULLTS}

The present study included the records of 20 patients with twenty teeth having a necrotic pulp and an incompletely formed apex. Four patients were excluded due to failure to follow up visits.

The patients were between 7 and 9 years of age. The average age of the patients was 8 years. There was significantly $(p>0.05)$ more boys $(62.5 \%)$ than girls $(37.5 \%)$. All the affected teeth were upper central incisors (Table 1).

The mean duration for apical barrier formation was $6.813 \pm 1.1$ months (range 6-12 months). Majority of the cases, about 60\%, needed 8-9 months for complete apical barrier formation, followed by $31.25 \%$ of cases required $6-7$ months, $18.75 \%$ of cases required $10-11$ 
months and only $12.5 \%$ of cases required 12 months and over to complete their apical barrier formation (Figure 6).

Table (1): Numbers and percentages of patients' distribution according to gender and age.

\begin{tabular}{|c|c|c|c|}
\hline \multirow{2}{*}{$\begin{array}{c}\text { Age } \\
\text { (Years) }\end{array}$} & \multicolumn{2}{|c|}{ Sex } & \multirow{2}{*}{ Total } \\
\cline { 2 - 3 } & Male & Female & \\
\hline $\mathbf{7}$ & $6(60.0 \%)$ & $2(33.3 \%)$ & $8(50.0 \%)$ \\
\hline $\mathbf{8}$ & $3(30.0 \%)$ & $4(66.7 \%)$ & $7(43.8 \%)$ \\
\hline $\mathbf{9}$ & $1(10.0 \%)$ & $0(0.0 \%)$ & $1(6.2 \%)$ \\
\hline Total & $\mathbf{1 0}(\mathbf{6 2 . 5 \%})$ & $\mathbf{6 ( 3 7 . 5 \% )}$ & $\mathbf{1 6}(\mathbf{1 0 0 \%})$ \\
\hline
\end{tabular}



Figure (6): Duration for apical barrier formation.

\section{DISCUSSION}

Daily there is a greater number of individuals who are victims of different types of accidents which can cause often irreversible trauma to dental structures and to their supporting system, depending on the intensity and form of trauma. ${ }^{(11)}$ In this study there was significantly more boys than girls suffering from dental trauma, this is in agreement with another study ${ }^{(12)}$ that found boys more active than girls at school age.

Traumatic injuries can cause a lot of complications, such as internal and external resorption, necrosis and calcification, ${ }^{(13)}$ showing the importance of preservation using periodic clinical and $\mathrm{x}$-ray exams to detect the presence of these pathological alterations.

Endodontic treatment of teeth with incomplete root formation seeks to obtain physiological complementation of the radicular apex (apexigenesis) or apical closure by means of stimulation (apexification) which is the objective of this study.

In this study all the affected teeth were upper central incisors, since these teeth are affected by trauma more than the other because their anterior position. ${ }^{(12)}$ Normally, they erupt at age of 6.7-8.1 years and complete root formation at age of 8.6-9.8 years ${ }^{(14)}$ that's why in this study the children with affected non-vital immature central incisors range between 7-9 years of age.

Diverse materials have been proposed to induce the apexification of nonvital permanent teeth. Morse $e t a l .{ }^{(15)}$ studied five treatment methods for teeth with incomplete root formation 
and pulpal necrosis and concluded that the success of therapy with apical tissue repair is due to the antibacterial action and the calcification-inducing action of calcium hydroxide.

Many studies demonstrated other materials being used for apexification, such as calcium hydroxide in combination with sterile water, saline, local anesthetic, camphorated parachlorophenol, zinc oxide paste with cresol and iodoform, ${ }^{(16)}$ polyantibiotic paste ${ }^{(17)}$ and tricalcium phosphate. ${ }^{(18)}$ There are new strides in the apexification procedure with mineral trioxide aggregate (MTA). ${ }^{(19)}$ But the use of calcium hydroxide in apical barrier formation has shown promising results. Because of its enhanced success rate, easy availability for clinician and affordability for patients, it has gained widest acceptance all around the world.

The alkalinity of non setting calcium hydroxide is used to stimulate the formation of mineralized and fibrous tissue by the granulation tissue cells in the apical part of the root canal. ${ }^{(20)}$ It stimulates the physical barrier and also acts as disinfectant. The resultant mineralized tissue can be composed of osteocementum, osteodentine, or bone or some combination of the three. The calcific bridge can be a complete or an incomplete hard tissue bridge at the root end or a few millimeters short of it. ${ }^{(21)}$

In this study complete apical barrier formation was occurred in $100 \%$ of the teeth with using tgpaste of calcium hydroxide with barium sulfate. This indicated that this product considered being excellent in inducing calcified apical barrier formation. Even other studies ${ }^{(22-26)}$ used calcium hydroxide of different sources, but they also gain very good result of apical closure.

Chosack et $a l_{.}^{(25)}$ suggested that repeated root fillings are not required as calcium hydroxide is only required to initiate healing process. They also reported that the calcium hydroxide has to be replaced if there are any symptoms or displacement of the medicament that was also used in this study, so calcium hydroxide paste was changed every 3 months when there was any evidence of displacement or resorption of the medicament. The frequency of calcium hydroxide dressing change is one of the few variables within the operator's control, which also has an effect on the speed of barrier formation. Hence it is confirmed that, if the root apex is disturbed by repeated instrumentation and dressing changes, then the time required for apex formation prolongs. ${ }^{(24)}$

It should be recognized that teeth treated by the apexification method are susceptible to fracture because of the brittleness that results from non-vitality and from the relatively thin dentinal walls of the roots. In addition, another important problem with the calcium hydroxide apexification technique is the duration of therapy, which often lasts many months. In this study the majority of cases required 8-9 months to complete the calcified apical barrier formation, meanwhile the range of all cases was 6 to 12 months, which is less than that found in other studies that reported in the absence of infection apexification can occur within 12 to 18 months. ${ }^{(27-30)}$ This may be related to availability and calcification-inducing action of different calcium hydroxide products.

\section{CONCLUSIONS}

It is generally agreed that calcium hydroxide is the major ingredient responsible for stimulating the desired calcific closure of the apical area of non-vital immature permanent incisors.

\section{REFERENCES}

1. Nagaveni NB, Umashankara KV, Radhika NB, Manjunath S. Successful closure of the root apex in non-vital permanent incisors with wide open apices using single calcium hydroxide $(\mathrm{CaOH})$ dressing - report of 2 cases. $J$ Clin Exp Dent. 2010; 2(1): 26-29. 
2. Sheely EC, Roberts GJ. Use of calcium hydroxide for apical barrier formation and healing in non-vital immature permanent teeth: A review. Br Dent J. 1997; 183: 241-246.

3. Cvek M. Endodontic management of traumatized teeth. In: Andreasen JO, Andreasen FM, eds. Textbook and Colour Atlas of Traumatic Injuries to the Teeth. $3^{\text {rd }}$ ed. Copenhagen: Munksgaard, 1994; p: 543.

4. Steiner JC, Van Hassel HJ. Experimental root apexification in primates. Oral Surg Oral Med Oral Pathol .1971; 31: 409-415.

5. Harrison JW, Rakusin H. Intracanal cementosis following induced apical closure. Endod Dent Traumatol. 1985; 1: 242-245.

6. Torneck CD, Smith J. Biologic effects of endodontic procedures on developing incisor teeth. I. Effect of partial and total pulp removal. Oral Surg Oral Med Oral Pathol. 1970; 30: 258-266.

7. Dylewski JJ. Apical closure of non-vital teeth. Oral Surg Oral Med Oral Pathol .1971; 32: 82-89.

8. Yang S-F, Yang Z-P, Chang K-W. Continuing root formation following apexification treatment. Endod Dent Traumatol. 1990; 6: 232-235.

9. Feiglin B. Differences in apex formation during apexification with calcium hydroxide paste. Endod Dent Traumatol. 1985; 1: 195-199.

10. Heithersay GS. Stimulation of root formation in incompletely developed pulpless teeth. Oral Surg Oral Med Oral Pathol. 1970; 29: 620-630.

11. Prokopowitsch I. Influence of calcium hydroxide in apexification (Study "in vitro"). MSc thesis, São Paulo, 1994; P: 123.

12. Welbury R. Paedriatric Dentistry. Oxford University Press, Oxford. Chapter 11. 1997; Pp: 225-251.

13. Bakland LK. Trauma Dental: Exame, Diagnóstico e Tratamento. In: Deus, Q.D. Endodontia. $5^{\text {th }}$ ed. Rio de Janeiro, Medsi, 1992.

14. McDonald RE, Avery DR, Dean JA. Dentistry for the Child and Adolescent. Mosby, Inc, St Louis. 2004 ; p: 303.

15. Morse DR, O'Larnic J, Yesilsoy C. Apexification: Review of the literature. Quint. Int. 1990; 21(7): 589-598.

16. Cooke C, Rowbotham TC. The closure of open apices in non-vital immature incisor teeth. Br Dent J. 1988; 165 : 420-421.

17. Rule DC, Winter GB. Root growth and apical repair subsequent to pulpal necrosis in children. Br Dent J. 1966; 120: $586-590$.

18. Coviello J, Brilliant JD. A preliminary clinical study on the use of tricalcium phosphate as an apical barrier. $J$ Endod. 1979; 5: 6-13.

19. Nuvvula S, Melkote TH, Mohapatra A, Nirmala S. Management of immature teeth with apical infections using mineral trioxide aggregate. Contemp Clin Dent. 2010; 1: 51-53.

20. Vojinović O. Induction of apical formation in immature teeth by different endodontic methods of treatment. Experimental pathohistological study. J Oral Rehabil. 1974; 1: 85-97.

21. Rafter M. Apexification: A review. Dent Traumatol. 2005; 21(1): 1-8.

22. Chawla HS. Apical closure in a nonvital permanent tooth using one $\mathrm{Ca}(\mathrm{OH}) 2$ dressing. ASDC J Dent Child. 1986; 53: 44-47.

23. Kinirons MJ, Srinivasan V, Welbury RR, Finucane D. A study in two centres of variations in the time of apical barrier detection and barrier position in non-vital immature permanent incisors. Int J Paediatr Dent. 2000; 11: 447-451.

24. Domingues RA and Muñoz L. Endodontics: Study of calcium hydroxide apexification in 26 young permanent incisors. Dent Traumatol. 2005; 21: 141-145.

25. Chosack A, Sela J, Cleaton-Jones P. A histological and quantitative histomorphometric study of apexification of nonvital permanent incisors of vervet monkeys after repeated root filling with a calcium hydroxide paste. Endod Dent Traumatol. 1997; 13: 211-217.

26. Trope M. Treatment of immature teeth with non-vital pulps and apical Periodontitis. Endodontic Topics. 2006; 14: $51-59$

27. Andreasen JO. Traumatic Injuries of the Teeth. $3^{\text {rd }}$ ed. Conpenhagen, Munksggard, 1984.

28. Tronstad L. Clinical endodontics. New York, Thieme Medical, 1991.

29. Linsuwanont P. ATTA apexification combined with conventional root canal retreatment, Aust Endod J. 2003; 29(1): 45-49.

30. Lee LW, Hsia SH, Chang CC, Chen LK. Duration for apical barrier formation in necrotic immature permanent incisors treated with calcium hydroxide apexification using ultrasonic or hand filing. J Formosan Medical Assoc. 2010; 109(8): 596-602. 